\title{
A Research on Employee Retention in Sacred Heart College (Autonomous), Tirupattur
}

\author{
S. Sasikumar, A. Rakini
}

\begin{abstract}
Many colleges experience increase in attrition and it has great impact on the performance of the colleges. Objective of this study is to find why employee are leaving their job and propose retention initiatives. The research instrument used to obtain data was questionnaire. A total 200 employees are there in the college. By using random sampling a total of 140 employees were interviewed using questionnaires. Correlation analysis is used to test the inter correlation between the variable. Correlation result shows that the two variables of motivation and job satisfaction were correlated with employee retention in the college. Same tool has been used to determine the relationship between the variables namely the relationship of the management with the staff and the factors influencing this relationship to grow stronger. Results indicate attrition is associated with compensation provided for the additional working hours to the staff and their selection process. These findings clearly indicate that in order to retain the best talented employees in the college, taking care of the employees by having good relationship with them is a must.
\end{abstract}

Keywords:--Employee Retention, Employee Satisfaction, Management.

\section{INTRODUCTION}

When the top performers quitting the college it becomes extremely difficult for any college to survive. So any employee who is effective and efficient must be retained for the college to survive, to sustain and to progress. Only such kind of employees can take the college forward. They need to remain hardworking and loyal to the college. When their dedication is achieved the college can easily reach their objectives. It is the ability of the college to see that the employees are retained. For this, they have to be motivated and encouraged within the same college. This will enable the college to save its resources. College also needs to see that they understand the employees and help them to resolve their problems. Therefore every college needs to spend sufficient time and energy to groom their own employees. If the employees quit the college after being fully trained it will be a heavy loss to the college. When the college is smaller in size, and if they lose their good employees it will have a greater impact in its growth. So employee retention is a must to keep the moral of the college along with that of the employees too.

The college in contention here is Sacred Heart College (Autonomous), Tirupattur, the second one of this kind in India by the Salesians of Don Bosco. It is affiliated as the first graded college to Thiruvalluvar University. The effort of Salesians in India with regard to education is not merely

Revised Manuscript Received on December 30, 2019.

S. Sasikumar, Assistant Professor \& Head, Department of Management Studies, Sacred Heart College (Autonomous), Tirupattur, Vellore Dt.- 635 601, Tamil Nadu, India.

A. Rakini, Research Scholar, Ph. D. Management (full time), Department of Management Studies, Sacred Heart College (Autonomous), Tirupattur, Vellore Dt. - 635 601, Tamil Nadu, IndiaIndia. to impart knowledge alone but is also meant to give values and skills which would develop them holistically. Their efforts do not merely stop with urban youth but is also for the rural ones. So tribal areas are targeted with special emphasis for the under privileged section of the society Here the courses offered are employment oriented, profession and student friendly which makes every student to come over to study. Though when the college started it had only 10 teaching staff with 81 students, today it has grown up to be a college which is accredited by NAAC and ranked in India as the $95^{\text {th }}$ government ranked college.

\section{LITERATURE REVIEWS}

'Employee Attrition and Retention Strategies in Manufacturing: An Empirical Study in Amara Raja Batteries Limited' by M. Sudheer Kumar \& et.al. (2019), is a study that attempts to pinpoint the features that motivate the workers to work and to remain on in the organization. For this purpose the study has utilized questionnaires to gather data and the processing and analysis part is done with the help of SPSS using descriptive and inferential statistics. The result shows that when job security is there and some understanding towards the employees are shown like giving necessary holidays, giving remuneration to employees as and when it is required, then it reduces the employees turnover. It is always a difficult task to identify the right talent for the right job for the employers. Even if one gets the correct talent, still to retain them becomes a difficult task. So efforts are to be made to see that timely training and development of the employees are taken care.

"A Study on Employee Retention in Education Sector in India with special reference to Noida Region" is written by Ruchi Tripathi \& et.al. (2017). It talks about the potential of the organization retaining its employees. Keeping the employees longer with the organization is good for the organization as well as for the benefit of the employees too. When the employees fine the job or the employer not satisfying enough they switch over their job to other jobs. So it is the major responsibility employer to provide with the necessary organization culture to keep them retrained. It also require, sufficient support, timely compensation and encouragement given to the employees. Maintaining good relationship with the employees is a must. In order to retain the employees there has to be also effort made to see that the customers are made to feel satisfied with the organization Satisfaction of the colleagues and timely reporting by the staff are also necessary factors to create and maintain good culture of the organization. 


\section{A Research on Employee Retention in Sacred Heart College (Autonomous), Tirupattur}

This article goes on to say that, in the current scenario in India, retention is a requirement and is promoted by job satisfaction with the better working condition and hike in salary. Article also states that it is a real necessity to have the retention of the best talent in the organization and also drop those talents that are not up to the mark. When employees feel that they are valued and trusted, the health and the success of the organization will certainly increase.

'Job Satisfaction - A Major Factor behind Attrition or Retention in Retail Industry' by Sarabjeet Kaural \& et.al. (2016), is a study that analyzes the advantages of job satisfaction. It says about employees work in the organization is not only for money, but they do so to develop their career as well. Too long working hours in the organization and treacherous works lead to employee attrition. When the employees are forced to do certain jobs it automatically creates anxiety in the minds of the employees.If the employees are to work for too long hours but salary is not proportionate to that, then there is a sense of dissatisfaction. Especially for the junior employees, when the supervisor does not show understanding again there will be problems for friction. Lack of timely training also keeps the employees as underperformers. Smart employees in the market are sought after even by MNC companies and so they grievance of the employees from within the organization have to be addressed if not they will walk away to other organizations

\section{OBJECTIVES OF THE STUDY}

- To find out the reasons for employees leaving the job

- To measure the employee satisfaction level with their job

- To identify factors affecting employee retention

- To identify factors contributing to employee retention

\section{IVHYPOTHESIS OF THE STUDY}

H0: There is a significant relationship between personal accomplishments and feeling recognized.

H0: There is a significant relationship between satisfaction with the job and the salary received.

H0: There is a significant relationship between clarity of the job and the utilization of the skills

H0: There is a significant relationship between understanding of my job profile and support given by the management.

\section{RESEARCH METHODOLOGY AND DATA ANALYSIS\& RESULTS}

This present study on employee retention in Sacred Heart College (Autonomous) Tirupattur, is exclusively based on the primary data. It is done in order to understand the level of employee satisfaction in the college and to know the motivational factors that make them to continue or to leave the job. This has been done with the help of questionnaires.

\section{VICORRELATION ANALYSIS}

Here all the calculated values as given in the table below, are below 1 which is < the table value @5\% i.e., = 2.58 . That is to say, there is significant relationship between all the factors like the personal accomplishment of the employees in the work, the recognition that one receives, the utilization of one's skills, facilities to perform ones work, possibilities of being more creative and innovative, having the need to have good communication level between the management and the employees, having one's voice heard in the decision making process, deriving satisfaction for one's job, getting sufficient opportunities to grow in one's career, getting the support of the colleagues to grow in life, having opportunities to grow as a person as well as updation of one's skills, knowledge and abilities, getting appreciation for one's expressed abilities, having the job requirements and the culture of the institution clear to oneself, getting sufficient salary and remuneration for the rendered service and the support and the understanding shown by the management.

\begin{tabular}{|c|c|c|c|c|c|c|c|c|c|c|c|c|c|c|c|c|c|}
\hline & 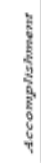 & $\begin{array}{l} \\
\vdots \\
\vdots \\
\vdots \\
\vdots \\
2\end{array}$ & 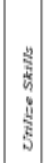 & 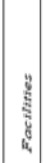 & 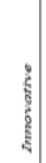 & 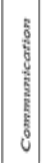 & 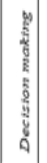 & $\begin{array}{l}0 \\
\vdots \\
\vdots \\
\vdots \\
\vdots \\
\vdots \\
\vdots\end{array}$ & $\begin{array}{l}\text { y. } \\
\vdots \\
\vdots \\
\vdots \\
\vdots \\
\vdots\end{array}$ & $\begin{array}{l}0 \\
\vdots \\
\vdots \\
\vdots \\
\vdots \\
\vdots \\
\vdots \\
\vdots\end{array}$ & : & $\begin{array}{l}y \\
y \\
y \\
y \\
y \\
5 \\
8 \\
0\end{array}$ & 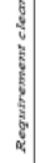 & $\begin{array}{l}0 \\
\text { s. } \\
\text { bे } \\
8 \\
0 \\
0 \\
0\end{array}$ & है & $\begin{array}{l}5 \\
5 \\
5 \\
5 \\
5 \\
0\end{array}$ & 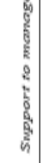 \\
\hline Accomplishment & 1 & & & & & & & & & & & & & & & & \\
\hline Recognized & 0.51 & 1 & & & & & & & & & & & & & & & \\
\hline Utilize Skills & 0.29 & 0.41 & 1 & & & & & & & & & & & & & & \\
\hline Faciltites & 0.64 & 0.26 & 0.63 & 1 & & & & & & & & & & & & & \\
\hline lanorative & 0.35 & 0.73 & 0.49 & 0.59 & 1 & & & & & & & & & & & & \\
\hline Communiction & 0.05 & 0.17 & 0.69 & 0.38 & 0.33 & 1 & & & & & & & & & & & \\
\hline Decision Making & 0.21 & 0.52 & 0.51 & 0.56 & 0.77 & 0.66 & 1 & & & & & & & & & & \\
\hline Satufified Job & 0.41 & 0.37 & 0.32 & 0.47 & 0.55 & 0.43 & 0.41 & 1 & & & & & & & & & \\
\hline Opportunities & 0.15 & 0.29 & 0.68 & 0.37 & 0.40 & 0.78 & 0.51 & 0.51 & 1 & & & & & & & & \\
\hline Supportmyc & 0.43 & 0.47 & 0.63 & 0.75 & 0.72 & 0.55 & 0.77 & 0.58 & 0.51 & 1 & & & & & & & \\
\hline Updation & -0.08 & 0.19 & 0.39 & 0.29 & 0.35 & 0.51 & 0.59 & -0.11 & 0.26 & 0.34 & 1 & & & & & & \\
\hline Efforts dralued & 0.18 & 0.16 & 0.54 & 0.46 & 0.27 & 0.80 & 0.63 & 0.15 & 0.62 & 0.32 & 0.62 & 1 & & & & & \\
\hline Requiremeat Cleas & 0.52 & 0.38 & 0.52 & 0.88 & 0.79 & 0.37 & 0.71 & 0.63 & 0.40 & 0.80 & 0.25 & 0.32 & 1 & & & & \\
\hline College Culture & 0.41 & 0.27 & 0.47 & 0.70 & 0.60 & 0.57 & 0.68 & 0.59 & 0.52 & 0.58 & 0.50 & 0.55 & 0.81 & 1 & & & \\
\hline Salary & 0.53 & 0.43 & 0.10 & 0.35 & 0.31 & 0.12 & 0.30 & 0.46 & 0.06 & 0.14 & 0.10 & 0.34 & 0.27 & 0.15 & 1 & & \\
\hline Other Benefits & 0.46 & 0.42 & 0.07 & 0.43 & 0.45 & 0.21 & 0.47 & 0.49 & .0 .04 & 0.32 & 0.33 & 0.39 & 0.46 & 0.47 & 0.78 & 1 & \\
\hline Support to manarement & 0.37 & 0.72 & 0.70 & 0.49 & 0.62 & 0.60 & 0.69 & 0.42 & 0.57 & 0.86 & 0.56 & 0.63 & 0.45 & \begin{tabular}{|l|l|}
0.47 \\
\end{tabular} & 0.35 & 0.60 & \\
\hline
\end{tabular}

Looking at their own life in the college as individuals. Employees when they look at their own personal accomplishment in the job $65 \%$ are very positive in their reply and another $16 \%$ on undecided stage. This is a positive stroke and the employees will remain loyal to the college. Even when it comes to being recognized as individuals with worth $52 \%$ are positive and another $24 \%$ are on the fence. When it is a matter of utilization of employees' skill still they are very positive with $69 \%$ speaking positive and another $15 \%$ still to decide. About having the required facilities to perform in their task too very good response of $74 \%$ going along with this statement is very nice for their retention. About having the possibilities of being innovative and creative, too employees have responded well with $53 \%$ positive about it and another $44 \%$ to make their decision on this. About overall satisfaction of their job too, basically a good response with $46 \%$ agreeing and $8 \%$ still to decide. But there is almost an equal number going on to negative 
line with $46 \%$. Here management will have to take notice to see the possibilities keep the employees in good humour if not there could be possibilities of losing the employees. When it comes to having colleagues giving supporting hand it is a mixed feeling. On the positive line there are $45 \%$ and on the negative line there are $19 \%$ and the undecided category is $36 \%$. So all will have to put their hands together to see that this matter is addressed as managers and employees themselves in their own forum.

When the employees speak about their management and the policies prevalent this is what they have got to say. It has been noticed that when the communication level between the management and the staff are cordial employees feel happy to carry out their task happily. Currently this college has this as one of their concerns for a total of $38 \%$ said that they are neither strongly agreeing nor agreeing with this matter. And another $31 \%$ preferred not to take any side. Which means a total of $69 \%$ are not finding this point as positive in the college currently. Their role in the decision making also is hardy seen and so there is so much dissatisfaction. There too $40 \%$ are speaking against this and another $23 \%$ are remaining undecided. So it also comes to $63 \%$. Management has to take note of this. As far as salary and remuneration that they receive is in alarming position. When $54 \%$ went negative in this line along with this another $15 \%$ still remaining as undecided as far as remuneration is concerned it is $40 \%$ on the negative line and $36 \%$ yet to decide. So management has to look seriously at this factors if not they may lose more employees.

Employees are happy with the opportunity they receive in the college to grow in their career and for this there is $47 \%$ agreeing to it and another $30 \%$ remaining undecided on to this factor. With regard to updation of their skills also there is a positive response from the side of the employee which comes around $44 \%$ and another $39 \%$ are still to decide. Employees are also decently happy with the recognition they receive from the management. There is a decent $\%$ of

47 to go along with this opinion and another $16 \%$ still to decide. $65 \%$ of employees are of the opinion that they are clear about what they should be doing. This is a commendable factor for the management. Knowing about the college culture and the way to function within it also commendable for there is $51 \%$ agreeing to it and another $31 \%$ still to decide. As far as the understanding shown by the management towards the employees are also praise worthy in as much as $40 \%$ is positive and $37 \%$ is yet to decide. That stands in good ground. This certainly enable the employees to remain on with their current job. 


\section{A Research on Employee Retention in Sacred Heart College (Autonomous), Tirupattur}

strengthened and for the new recruits it only becomes a matter of time to venture into the same to be part of it all. Quality of the work will be kept up by the dedicated and loyal employees who have been retained. Problem solving and workflow normally does not get interrupted since there is a system in place. So let more efforts be made in the line retention by the college to grow and develop to be a centre of excellence and prosperity.

\section{REFERENCES}

1. M. Sudheer Kumar, Obulesu Varikunta \& K. Ramakrishna "Employee Attrition and Retention Strategies in Manufacturing: An Empirical Study in Amara Raja Batteries Limited", International Journal of Innovative Technology and Exploring Engineering (IJITEE), Vol. 8 (Issue .7), May 2019, pp.29 - 62.

2. Ruchi Tripathi \& Vinay Pratap Singh "A Study on Employee Retention in Education Sector in India (with special reference to Noida Region)", International Journal of Research in Management \&Business Studies (IJRMBS) Vol.4 (Issue: 4) 2017, p. 76

3. Sarabjeet Kaural \& Ritu Vijay "Job Satisfaction - A Major Factor Behind Attrition or Retention in Retail Industry", Imperial Journal of Interdisciplinary Research (IJIR), Vol.2 (Issue.8), 2016, p. 993.

4. https://en.wikipedia.org/wiki/Employee_retention

5. https://www.managementstudyguide.com/employee-retention.htm

6. https://www.forbes.com/sites/steveolenski/2015/03/03/7-tips-tobetter-employeeretention/\#209a05b845 2b

7. http://www.shctpt.edu/aboutus.php 